\title{
Ser coadjuvante ou protagonista no cenário político: o impasse das primeiras-damas
}

\author{
Be supporting or protagonist on political scenary: the deadlock of the first ladies
}

\author{
Dayanny Deyse Leite Rodrigues \\ https://orcid.org/0000-0003-2866-2981 \\ Universidade Federal de Goiás
}

\begin{abstract}
Resumo: O papel de primeira-dama na cultura política brasileira dos séculos XX e XXI se constituiu enquanto uma figura marcada pelas relações de gênero e fomentada para atuar de forma a legitimar os anseios políticos do Estado. Esse papel começou a ser delineado na passagem da década de 1930 para 1940, momento em que Darcy Vargas, por meio de sua trajetória de atuação junto à serviços assistenciais, cria e assume a presidência do primeiro órgãos governamental de assistência social do Brasil, a Legião Brasileira de Assistência - LBA. Ao ser redigida, no decorrer dos anos 2000, a frase "bela, recatada e do lar", fazendo referência a primeira-dama do país, Marcela Temer, evidencia-se como os atributos ditos "femininos" são utilizados para encorpar a figura social da primeira-dama. Dessa forma, o trabalho tem como objetivo discutir a constituição social do papel de primeira-dama na sociedade brasileira pontuando sua relação com a discussões em torno das questões de gênero, bem como discutir se as atuações dessa figura social se apresentam enquanto protagonistas ou coadjuvantes no campo político brasileiro. O estudo foi desenvolvido sob a perspectiva da História Política dita "Renovada" e dos Estudos de Gênero". O papel de primeira-dama figura-se entre o protagonismo e o coajduvantismo. Vale destacar que embora esse papel social tenha sido pensado e elaborado como meio de suporte às práticas dos esposos governantes, muitas primeiras-damas exerceram papel de destaque, construindo trajetória de atuação própria.
\end{abstract}

Palavras-chave: Primeira-dama. Assistencialismo. Gênero.

Abstract: The role of first lady in the Brazilian political culture of the $X X$ and $X X I$ centuries was constituted as a figure marked by gender relations and encouraged to act in order to legitimize the political desires of the State. This role began to be delineated in the passage of the 1930s to 1940, when Darcy Vargas, through his trajectory of work with welfare services, created and assumed the presidency of Brazil's first government social welfare agency, the Brazilian Legion of Assistance - LBA. In the course of the 2000s, the phrase "beautiful, modest and of the home", referring to the first lady of the country, Marcela Temer, shows how the so-called "feminine" attributes are used to encourage the social figure of the first lady. Thus, the work aims to discuss the social constitution of the role of the first lady in Brazilian society, punctuating her relationship with discussions around gender issues, as well as to discuss whether the actions of this social figure are presented as protagonists or supporting actors in the Brazilian political field. The study was developed from the perspective of so-called "Renewed" Political History and Gender Studies. The role of first lady is between protagonism and coajduvantism. It is worth mentioning that although this social role was thought and elaborated as a means to support the practices of the governing spouses, many first ladies played a prominent role, building their own path of action.

Keywords: First Lady. Assistance. Gender.

Esta obra está licenciada sob uma Creative Commons - Atribuição 4.0 Internacional 


\section{Primeira-dama, como esse papel social se constituiu?}

Se partirmos de uma análise semântica do termo "primeira-dama", levaremos em consideração o significado inicial das duas palavras que formam tal expressão. A primeira definição do termo "dama" apresentado pelo dicionário Priberam de Língua Portuguesa é "Senhora nobre ou de distinção". Primeira-dama seria então a primeira das damas nobres e distintas de uma determinada sociedade. Constituída enquanto expressão socialmente relacionada às esposas dos governantes, a expressão "primeiradama", de acordo com os dicionários Priberam de Língua Portuguesa ${ }^{1}$ e Aurélio Online ${ }^{2}$, é o substantivo atribuído à "esposa de um governante, geralmente de um presidente". No campo político a expressão foi utilizada pela primeira vez em meados do século XIX, nos Estados Unidos, momento em que o Presidente Zachary Taylor (1849-1850) o teria utilizado para referir-se à Dolley Payne Todd Madison, mulher de um de seus antecessores, James Madison, na cerimônia fúnebre dela. Nessa perspectiva, a terminologia "primeira-dama", no decorrer dos séculos XX e XXI, passou a fazer referência direta as esposas de governantes, em especial aqueles em exercício em cargos no poder executivo. Vale destacar que "primeira-dama" não é um título oficial, nem carrega prerrogativas ou direitos exclusivos, mas exerce, ou pode vir a exercer, papel de destaque na administração de seus cônjuges e no desenvolvimento de possíveis capitais políticos ${ }^{3}$.

No Brasil, mesmo alguns estudos considerando que Dona Leopoldina seria a primeira personalidade a ocupar tal posição, a primeira mulher de um governante a estruturar um modelo de atuação do que se convencionou chamar de primeira-dama foi Darcy Vargas, esposa do presidente Getúlio Vargas (1930 - 1945/1951 - 1954).

É a partir das décadas de 1930 e 1940 que o papel social da primeira-dama começa a se configurar no cenário brasileiro. Em meio a um processo de gestão política racional ligado a necessidade do Estado se fazer presente no cenário social, a figura da primeira-dama é moldada. Em plena década de 1940, o Estado se viu obrigado a dar maior atenção aos problemas sociais, e a mulher do governante passa a ocupar um papel estratégico nessa ação. A questão social passou a ser debatida. Nessa conjuntura, o Estado Novo passou a desenvolver formas para conquistar o apoio das massas. Como ressalta Capelato, "além da busca de apoio, a integração política das massas visava o seu controle em novas bases" (Capelato, 2003, p. 111). O Estado então recorre aos valores socialmente difundidos como femininos para sensibilizar a sociedade a intervir na "questão social", impulsionando o espírito filantrópico a partir de práticas assistencialistas, características da ação projetada para a primeira-dama da Nação. (RODRIGUES, 2017, p. 02)

Fazendo referência a este fenómeno, Iraildes Torres (2002) destaca que "Nesse caso específico do nascedouro do primeiro-damismo, há uma motivação política: o Estado brasileiro vê-se obrigado a forjar estratégias de enfrentamento dos problemas sociais que assumem sérios contornos nesse período da Segunda Guerra" (TORRES, 2002 , p. 39-40). As esposas de governantes entram em cena e dessa forma "as atividade de filantropia/assistencialismo acabam determinando a identidades social das primeiras-damas, fato que parece difícil de depurar-se, posto que encontra-se arraigado ao imaginário social das classes subalternas" (TORRES, 2002, p. 40).

\footnotetext{
${ }^{1}$ https://www.priberam.pt/dlpo/primeira-dama. Acesso em 07 de abr. 2019.

2 https://dicionariodoaurelio.com/primeira-dama. Acesso em 07 de out. 2018.

${ }^{3}$ De acordo com Pierre Bourdieu, Capital Político é uma "forma de capital simbólico, crédito firmado na crença e no reconhecimento ou, mais precisamente, nas inúmeras operações de crédito pelas quais os agentes conferem a uma pessoa os próprios que eles lhes reconhecem" (Bourdieu, 2011, p. 187-188).
} 
Diante do exposto, o trabalho tem como objetivo discutir a constituição social do papel de primeira-dama na sociedade brasileira pontuando sua relação com a discussões em torno das questões de gênero, bem como discutir se as atuações dessa figura social se apresentam enquanto protagonistas ou coadjuvantes no campo político brasileiro. O estudo será desenvolvido sob a perspectiva da História Política dita "Renovada" e dos Estudos de Gênero"4.

Dessa forma, entender a ação social e política de Darcy Vargas se torna ponto crucial para a compreensão da constituição do modelo de primeira-dama no Estado Brasileiro. Mas quem foi Darcy Vargas? Nascida "em 1895, em uma família de elite da cidade de São Borja, no Rio Grande do Sul (o pai era estancieiro e comerciante), casouse aos 15 anos com Getúlio Vargas em 1911, em sua cidade natal, e teve cinco filhos: Lutero (1912), Jandira (1913), Alzira (1914), Manoel Antônio (1916) e Getúlio (1917)" (SIMILI, 2008, p. 23).

Durante a "Era Vargas", Darcy atuou de forma incisiva na vida pública brasileira. Apesar de "falar pouco", muito fez pela questão social, principalmente pela infância e pelas famílias dos envolvidos da Segunda Guerra Mundial. De acordo com Simili (2008), "Após o suicídio de Getúlio Vargas, em 24 de agosto de 1954, Darcy teria passado a dedicar todo o seu tempo às atividades assistenciais, particularmente à casa do pequeno jornaleiro, que fez questão de administrar até morrer, em 1968" (SIMILI, 2008, p. 196- 197). Aos 72 anos, mesma idade que Getúlio se suicida, Darcy vem à óbito devido a complicações de um câncer.

25 de junho de 1968. O Rio de Janeiro ferve. Diversos grupos organizando uma grande passeata contra a ditadura militar. Enquanto os opositores da ditadura confabulavam e programavam o protesto, os familiares e amigos mais chegados de Darcy Vargas, no quarto andar do edifício número 392 da Praia do Flamengo, sofriam, alheios a todo esse movimento que se articulavam tanto em surdina. Seu estado de saúde havia piorado muito na últimas horas. Às 4 horas da madrugada daquele dia (25 de junho 1968), o câncer que a consumia havia cerca de um ano

\footnotetext{
${ }^{4}$ Este trabalho segue a perspectiva da "Nova" História Política. Não aquela História Política Tradicional que vigorava entre os fazeres historiográficos do século XIX, que valorizava apenas as instituições do Estado, os feitos dos "grandes homens" e os eventos de curta duração, mas uma história política que está ligada à discussão do estudo de micropoderes num ambiente cotidiano, no interior da família, nos discursos populares e nos grupos minoritários, como as mulheres. Mais informações ver: FOUCAULT, Michel. Microfísica do poder. Organização e tradução de Roberto Machado. Rio de Janeiro: Edições Graal, 1979. RÉMOND, René. (Org.). Por uma História Política. Tradução de Dora Rocha. Rio de Janeiro: FGV/UFRJ, 1996. MOTTA, Rodrigo Pato (org.). Cultura Política na História: novos estudos. Belo Horizonte: Argumentum/FAPEMIG. 2009. JULLIARD, Jacques. A Política. In: LE GOFF, Jacques; NORA, Pierre. História: Novas Abordagens. Rio de Janeiro: Francisco Alves, 1995, p. 180-196. Sobre as discussões de Gênero ver: BUTLER, Judith. "Fundamentos contingentes: o feminismo e a questão do 'pós-modernismo'”. Cadernos Pagu, n. 11, p. 11-42, 1998. BUTLER, Judith. Problemas de gênero: feminismo e subversão da identidade. Tradução, Renato Aguiar. Rio de Janeiro: Civilização Brasileira, 2003. CARVALHO, J. J. O olhar etnográfico e a voz subalterna. IN: Horizontes Antropológicos. vol.7, no.15. Porto Alegre, jul. 2001. DUBY, Georges; PERROT, Michelle. História das Mulheres no Ocidente: O Século XX. São Paulo: Ebradil, 1991. CONNELL, Raewin; PEARSE, Rebecca. Gênero: uma categoria global. São Paulo: Versos. 2015. [Tradução e revisão técnica: Marília Moschkovich]. LAURETIS, Teresa de. A tecnologia do gênero. In: HOLLANDA, Heloisa Buarque de. Tendências e impasses: o feminismo como crítica da cultura. Rio de Janeiro: Rocco, 1994. p. 206-242. RANGEL, Lívia de Azevedo Silveira e NADER, Maria Beatriz. História das mulheres e estudos de gênero: Identidade e relações de poder. In: Mulher e Gênero em Debate: Representações, poder e ideologia. Vitória: EdUFES, 2014, p. 109-118. SCOTT, Joan. OS USOS E ABUSOS DO GÊNERO. Projeto História, São Paulo, n. 45, pp. 327-351, Dez. 2012. [Tradução: Ana Carolina E. C. Soares]. SCOTT, Joan. Emancipação E igualdade: uma geneealogia crítica. OPSIS: Dossiê Relações de gênero, História, Educação e Epistemologias Feministas / Universidade Federal de Goiás, Regional Catalão. v. 15. n. 2 (2015). Pp 537 - 555. [Tradução: Ana Carolina Eiras Coelho Soares]. SPIVAK, Gayatri. Pode o subalterno falar? Belo Horizonte: UFMG, 2010. SEGATO, Rita Laura. Os percursos do gênero na Antropologia e para além dela. Brasília, Unb, 1998. Série Antropologia.
} 
levou-a deste mundo. Estava com 72 anos, a mesma idade que tinha Getúlio quando deu um tiro no coração. (CALLADO, 2011, p. 276- 277)

O exposto acima evidencia que a vida pública de Darcy Vargas começa mesmo antes dela ocupar o papel de primeira-dama do Brasil. Ao assumir a responsabilidade pelos problemas sociais a partir da criação da Legião Brasileira de Assistência, órgão que será aprofundado mais à frente, Darcy coloca em prática uma série de práticas já efetivadas por ela desde o início de 1930. A criação da Legião da Caridade foi o primeiro passo de Darcy Vargas junto à esfera social, fato ocorrido anteriormente à chegada de Getúlio Vargas ao poder, durante o desenrolar do movimento revolucionário de 1930. Buscando participar do movimento, Darcy cria a legião, "uma associação de mulheres organizada com o objetivo de produzir roupas para os revolucionários e distribuir alimentos para as famílias cujos membros acompanharam Getúlio" (SIMILI, 2008, p. 10). A Legião teve atuação concentrada no estado do Rio Grande do Sul e logo após o fim da revolução de 1930 se exauriu. Getúlio Vargas assume o governo provisório do país e Darcy se torna primeira-dama da nação. Alocada na capital da república, a gaúcha continuou seu trabalho junto à esfera social.

Sua atuação em obras dessa natureza parece ter começado em 1934, quando apoiou a fundação do Abrigo Cristo Redentor (RJ). Outras iniciativas seguiram-se a essa, tais como a de um abrigo para mendigos, a Escola de Pesca Darcy Vargas e a Escola Agrícola Getúlio Vargas. Em 1938 atuou na criação da Fundação Darcy Vargas destinada a oferecer assistência a menores e a coordenar escolas para crianças e idosos. Em 1940, inaugurou a Casa do Pequeno Jornaleiro, que prestava serviço de atenção à infância. Nos anos de 1940 expandiu essas atividades com a Casa do Pequeno Lavrador, a colônia de férias da casa do Pequeno Jornaleiro, a Escola Primária Álvaro Sodré e o restaurante da casa do Pequeno Trabalhador. Em 1942, foi responsável pela Legião Brasileira de Assistência (LBA) que herdara alguma finalidades da antiga Legião de Caridade, mas que adquirira novas funções no quadro da administração pública. A LBA incumbiu-se de múltiplas atividades em todo país, tornando-se o principal órgão de assistência social do governo brasileiro. (SIMILI, 2008, p. 10-11)

Os espaços de experiência pelos quais Darcy perpassou e fez uso para constituir o modelo de ação das primeiras-damas foram principalmente A Casa do Pequeno Jornaleiro e a Legião Brasileira de Assistência. No contexto de pouca ou nenhuma assistência governamental aos problemas sociais, Darcy se depara com uma degradante realidade enfrentada pela infância na capital da república.

A Casa do Pequeno Jornaleiro foi um projeto idealizado e concretizado no interior da Fundação Darcy Vargas, que tinha por objetivo, como aponta o artigo $3^{\circ}$ do seu regimento interno, "não só a curar, amparar e educar a infância desvalida da cidade do Rio de Janeiro, como também promoveu ensino profissionalizante de menores de ambos os sexos, com o objetivo de preparar os moral e fisicamente para uma vida útil, modesta e feliz". Dentro desse projeto maior se delineia a proposta da Casa do Pequeno Jornaleiro, destinada às crianças cujo seu tempo destinavam à atividades de vendas de jornais das rumas barulhentas do Rio de Janeiro.

A casa foi construída em um terreno doado pelo Governo Federal, contando com um restaurante para uso exclusivo de seus beneficiários. A unidade fornecia peças de vestuário, calçado, roupa lavada e outras utilidades incumbindo-lhe hábitos de poupança de economia e de Amor ao trabalho (Artigo $5^{\circ}$ do Regimento Interno da Fundação Darcy Vargas). Visivelmente o projeto seguia uma lógica assistencialista e filantrópica de ação junto aos menores, atribuindo-lhes direitos mas também deveres, 
bem como o espírito de trabalhadores a serviço da nação ${ }^{5}$. Lembremos que a "cidadania", no transcorrer das décadas de 1930 e 1940, estava ligada ao trabalho.

O conceito chave que permite entender a política econômica-social pós 30 , assim como fazer a passagem da esfera da acumulação para a esfera da equidade, é o conceito de cidadania, implícito na prática política do governo revolucionário, tal conceito poderia ser descrito como "cidadania regulada", ou seja, são cidadãos todos aqueles membros da comunidade que se encontrarem localizados em qualquer das ocupações reconhecidas e definidas em lei. A cidadania, portanto, está ligada à profissão, peitos como cidadão resumem-se naqueles referentes a posição ocupada por ele no processo produtivo e de acordo com que a lei reconhece. (SANTOS, 1994, p. 75)

Capelato (2003) também destaca essa relação estabelecida entre cidadania e trabalho. O cidadão seria o trabalhador. O bom trabalhador seria aquele a serviço da nação ${ }^{6}$. Segundo Maria Luiza Marcílio (1998, p. 215), o modelo filantrópico existente nos anos 1930 tinha "por escopo preparar o homem higiênico (capaz de viver bem nas grandes cidades, em boa forma e com boa saúde), formar o bom trabalhador, estruturar o cidadão normatizado e disciplinado. A utopia filantrópica almejava uma cidade harmônica, estável, feliz". Complementa Simili (2008):

Educar para o trabalho, transformar os jovens em trabalhadores fisicamente fortes, porém dóceis, disciplinados e bem comportados, resumo das práticas instituídas pela Fundação com os horários regrando a vida e o cotidiano da casa, as premiações pelo Bom Comportamento, as modalidades de lazer, tais como piscinas em Campos de Recreio, para criar o "homem higiênico". (SIMILI, 2008, p. 106)

Darcy Vargas atuou de forma intensa na Casa do Pequeno Jornaleiro até sua morte. Uma de suas marcas nessa passagem foi a realização de festividades caritativas convertidas em "ajuda" à casa. No contexto descrito, a organização de reuniões, chás e festas beneficentes era tido como práticas filantrópicas desenvolvidas pelas mulheres. Historicamente, esse tipo de atuação feminina foi incentivada em meio às relações sociais de gênero, pois eram vistas como "naturais" pelos homens e pela sociedade. As mulheres estariam propensas para a caridade, a bondade e o amor ao próximo. "Uma das razões para o incentivo masculino era o de que o envolvimento da mulher com a filantropia não significava o abandono da família, dos filhos, pois doavam o que tinha para dar 'tempo livre' e 'amor aos desamparados'” (SIMILI, 2008, p. 121).

Seguindo o que já vinha desenvolvendo à frente da Fundação Darcy Vargas, em especial na Casa do Pequeno Jornaleiro, a esposa de Getúlio soma em sua trajetória política a articulação e fundação da Legião Brasileira de Assistência (LBA), primeira instituição pública de assistência social do Brasil. "Mãe da pobreza, lar do carente, socorro dos Aflitos" foram as imagens populares associadas à Legião Brasileira de Assistência no Brasil, durante o seu período de existência (SPOSATI e FALCÃO, 1989,

\footnotetext{
${ }^{5}$ Documentos sobre a Casa do Pequeno Jornaleiro disponível para acesso na pasta "Documentos sobre a Fundação Darcy Vargas e a Casa do Pequeno Jornaleiro, como pedidos, votos de pêsames, congratulações, cartas de apresentação, agradecimentos, convites e homenagens". http://www.fgv.br/cpdoc/acervo/arquivo pessoal/AVAP/textual/documentos-sobre-a-fundacao-darcy-vargase-a-casa-do-pequeno-jornaleiro-como-pedidos-votos-de-pesames-congratulacoes-cartas-de-apresentacao agrade. Acesso em 12 de jan. 2019.

${ }^{6}$ CAPELATO, Maria Helena. O Estado Novo: o que trouxe de novo? In: FERREIRA, Jorge; DELGADO, Lucília de Almeida Neves (Orgs). O Brasil Republicano. O tempo do nacionalismo-estatismo - do início da década de 1930 ao apogeu do Estado Novo. Livro 2. Rio de Janeiro: Civilização Brasileira, 2003. p. 107114.
} 
p. 09). A instituição coexistiu com outros órgãos de assistência social no cenário brasileiro até 1995, quando foi extinta pelo governo Fernando Henrique Cardoso e substituída pelo programa comunidade solidária, este também presidido pela primeiradama, Ruth Cardoso (SIMILI, 2008, p. 131).

Como destaca Iraildes Torres (2002), "A legião Brasileira de Assistência vai constituir o grande marco dos empreendimentos das primeiras-damas no Estado brasileiro" (TORRES, 2002, p. 39). Foi por meio da atuação de Darcy Vargas frente à problemática social, agindo na presidência da LBA, que se constituiu no Brasil o que chamamos de "modelo de atuação das primeiras-damas". Ou seja, o ser primeira-dama foi racionalmente pensado e estruturado na sociedade brasileira, seguindo o transcorrer dos acontecimentos políticos e sociais do momento. Quanto a essa estruturação destaca Torres (2002):

O nosso estudo demonstra também que é identidade social das primeiras-damas começa a ser construída tendo como cortina de fundo as atividades assistencialistas que historicamente elas desenvolveram no Brasil. Essas atividades são realizadas dentro de instituições de bem-estar social criados especialmente para elas, o brasileiro como é o caso da legião Brasileira de assistência - LBA, e de outras instituições filantrópicas. (TORRES, 2002, p. 193)

Corroborando com o pensamento de Torres (2002), Simili nos alerta sobre o revestimento político que o papel de primeira-dama sofreu em seu processo de institucionalização.

Ao examinar a trajetória filantrópico-assistencial de Darcy Vargas, desenvolveu-se o argumento de que suas ações sociais e assistenciais - que tiveram início em 1930 com a criação da Legião da Caridade, prosseguindo em 1938 com a Fundação Darcy Vargas -, foram propícias para o estabelecimento de um modelo de atuação e de participação da primeira-dama nos meandros do poder presidencial. Em 1942, com a criação da Legião Brasileira de Assistência, essa mulher tornou-se, então, responsável pelo social. Ao coordenar o projeto assistencial do Estado, um papel significativo foi a ela concedido na condução da assistência social, para o viés assistencialista de que se revestiu essa política pública e que ainda orienta procedimentos no campo dos direitos políticos em nosso país. (SIMILI, 2008, p. 21)

Num contexto de forte mobilização feminina, lutando em prol de diferentes direitos das mulheres, dentre os quais estava o direito ao voto, Darcy Vargas construía um percurso como esposa de um homem público, com uma atuação pública e política e como mãe de seus filhos, estruturando e moldando o que se constituiu enquanto o papel social da primeira-dama. A arte de fazer da primeira-dama, o que chamamos de primeiro-damismo, se institucionalizou e se consolidou no país caminhando entre estratégia e tática. As noções de estratégia e táticas são formuladas por Michel de Certeau em uma análise das práticas cotidianas. Para Certeau (1994) a estratégia é "o cálculo das relações de força que se torna possível a partir do momento em que um sujeito de querer e poder é isolável de um 'ambiente"' (CERTEAU, 1994, p. 46). A estratégia tem, dessa forma, um lugar próprio e pode ser observada, segundo o autor, em questões relacionadas à nacionalidade política, econômica ou científica. A estratégia "postula um lugar capaz de ser circunscrito como um próprio e, portanto, capaz de servir de base a uma gestão de suas relações com uma exterioridade distinta" (CERTEAU, 1994, p. 46).

$\mathrm{Na}$ contramão das estratégias, as táticas são apontadas enquanto ações "desviacionistas", que geram efeitos imprevisíveis. Em oposição às estratégias, que 
buscam produzir, mapear e impor regras, modelos, situações, etc., as táticas possibilitam diferentes maneiras de fazer, sendo resultado das astúcias dos consumidores (agentes) e de suas capacidades inventivas. As táticas possibilitam aos indivíduos a capacidade de escaparem às empresas de controle e tomarem-se parte no jogo em questão.

A trajetória construída por Darcy Vargas é expressiva do entrecruzamento daquilo que Certeau chamou de estratégia e tática, sendo sua atuação caracterizada pela liberdade de ação junto ao social diante do posto ocupado, corroborando com o projeto de governo curso, mas fazendo uso dos sistemas normativos e da máquina administrativa a sua maneira. Por meio do envolvimento da personagem com as "políticas" de Getúlio Vargas foi possível que ela criasse um itinerário próprio que definiram um perfil para a mulher pública e primeira-dama como preocupada e vinculada às questões sociais e assistenciais. Esse modelo foi e continua sendo seguido por diversas primeiras-damas Brasil a fora, nos três níveis de governabilidade.

A LBA foi pensada e fundada enquanto espaço de atuação das primeiras-damas. "[...] essa instituição foi crida especificamente para o trabalho de Dona Darcy Vargas, sendo posteriormente dirigida por outras primeiras-damas" (TORRES, 2002, p. 94). Dessa forma, durante o período de existência, todas as esposas dos presidentes da república ocuparam a presidência da instituição e responderam pela área social do governo, com exceção da época do regime militar, momento em que as primeiras-damas se mantêm "afastadas" dos espaços destinados à assistência social. A historiografia aponta um desaparecimento da atuação das primeiras-damas, em nível federal, destacando um retorno com Roseane Collor, esposa de Fernando Mello de Collor. O primeiro-damismo segundo Falcão (1990), 'volta a ressurgir na era Collor', quando se configura a presença da primeira-dama, Sra. Rosane Collor, frente à Fundação Legião Brasileira de Assistência - LBA, como ações clientelísticas e filantrópicas. Indo de encontro com essa afirmativa, destacamos que o primeiro-damismo não desaparece e retorna apenas na década de 1990. Quando observadas as atuações de diversas primeiras-damas em níveis estaduais, por todo o território brasileiro, são percetíveis a atuação ativa destas.

No Nordeste brasileiro algumas primeiras-damas tiveram atuações de destaque na passagem das décadas de 1970 e 1980, muitas delas chegando a ocupar cargos políticos. Dentre alguns nomes destacamos Lúcia Braga (Paraíba), Wilma de Faria (Rio Grande no Norte) e Luiza Távora (Ceará). Optamos, então, por falarmos em um processo de mudança de faceta e eclipses do primeiro-damismo, o qual no plano federal não esteve tão atuante até os anos de 1990, mas que se mantém com grande força nos estados brasileiros. Na década de 1990 duas primeiras-damas aparecem no cenário político atuando junto à esfera social, Roseane Collor e Ruth Cardoso. "Com a extinção da LBA e a instituição do programa comunidade solidária, a Assistência Social continuou em muitos aspectos sob a conduta das Esposas dos governantes" (SIMILI, 2008, p. 132).

Fechando, por hora, esse ponto da discussão apontamos que por intermédio da trajetória traçada pela personagem Darcy Vargas, constituiu-se o processo de criação de um modelo instrucional de atuação e de participação da mulher na política assistencial brasileira, ou seja, a atuação de Darcy Vargas junto ao social se constituiu enquanto um modelo de atuação para as primeiras-damas futuras, fato que foi seguido, se observarmos o itinerário das esposas de governantes pós Darcy. Assim, definiremos "primeiro-damismo" enquanto um fenômeno de longa duração, caracterizado por um 
conjunto de práticas exercida pelas esposas de governantes em exercício no poder executivo, que podem ser apontadas enquanto estratégia, ao buscar legitimar a ideologia ou o projeto político do esposo, mas também enquanto tática, ao burlar a sua organização racional e funcional, podendo ser apropriado de diferentes maneiras, corroborando com o processo de constituição de possíveis capitais políticos próprios e a demarcação de espaços de atuação na "esfera pública". Esse fenômeno foi constituído e perpetuado sob o signo das hierarquias de gênero que marcaram a sociedade patriarcal, característica da sociedade brasileira.

\section{Onde e porque elas (as primeiras-damas) atuavam e/ou atuam?}

Como apontado na discussão anterior, o modelo institucional do que se convencionou enquanto a figura da primeira-dama na sociedade brasileira tem como norte de atuação o espaço do assistencialismo e da filantropia, práticas entendidas enquanto suportes sociais. "As grandes instituições assistenciais e previdenciárias emergem assim como parte dos esforços reformadores do Estado para responder às pressões das novas forças sociais urbanas" (IAMAMOTO, 1992, p. 35). As esposas dos governantes têm nesses espaços seu locus de atuação.

A Legião Brasileira de Assistência - LBA - nasce nesse contexto de necessidade da presença do Estado nos setores sociais, no entanto, sem priorizá-los.

A primeira instituição pública na área da assistência social foi a Legião Brasileira de Assistência - LBA, criada em 1942 com o objetivo de trabalhar em favor do progresso do Serviço Social, ao mesmo tempo que procura canalizar e conseguir apoio político para o governo, através de sua ação assistencialista. A primeira presidente dessa instituição foi Dona Darcy Vargas, primeira-dama do Brasil à época e esposa do então presidente Getúlio Vargas. (TORRES, 2002, p. 29)

Constituiu-se a partir da década de 1940 o espaço propício para a atuação das primeiras-damas da nação. A presença dessas mulheres fora do lar se apresentava enquanto um serviço ao país, tendo em vista que essas esposas teriam que fazer uso de seus atributos de mãe e esposa para melhor administrar os problemas sociais. Esse tipo de atuação pode ser entendido ainda como uma forma de atuação feminina cabível nos movimentos políticos realizados pelos homens. June Hahner (1981, p. 45) abordou esse aspecto ao lembrar que, em diferentes momentos da história política brasileira, as mulheres foram chamadas a participar das lutas masculinas, a exemplo das lutas abolicionistas. Darcy Vargas cumpre esse papel na passagem da década de 1930 para 1940, assumindo uma posição junto ao governo de seu esposo, no entanto, preservando-se numa posição tida como secundária, preservando a diferença da atuação de gênero. Nessa perspectiva, cabia "ao homem a discussão e ação política, às mulheres, as festas e outras formas de arrecadação de fundos. É com esse mesmo sentido que aparece a atuação da esposa de Getúlio Vargas" (SIMILI, 2008, p. 40).

Vale destacar que tais práticas assistencialistas nada tem a ver com programas governamentais constituídos em políticas públicas. Num período em que a questão social é "caso de polícia e não de política", como destaca Cerqueira filho (1982, p. 52), os problemas de cunho social não possuíam legitimidade para serem "atendidos" pelo Estado. Às mulheres dos governantes, enquanto representantes do Estado, coube então esse papel. Até a entrada das primeiras-damas em cena, "o tratamento dispensado pelo Estado da questão social na primeira república que não é considerado um problema público, fez que a área da assistência estivesse quase exclusivamente 
nas mãos das associações particulares, a exemplo de irmandades religiosas" (CARVALHO, 2001, p. 61). Os desvalidos da nação, aqueles cujo trabalho social se voltava, eram "atendidos" por instituições como:

para infância, os orfanatos, algumas creches, alguns lactalis; entidades filantrópica assistencial para cegos, surdos, filhos de tuberculosos, leprosos etc.; para a assistência aos velhos e às famílias desvalidas, os asilos de velhice, as vilas dos pobres, os dispensários e ação domiciliar das Conferências Vicentinas e das damas de caridade; na assistência ao trabalhador, os círculos operários, em seus primeiros anos de vida. (PINOTTTI et Al., 1958)

Diante dessa conjuntura, enquanto os problemas relacionados à pobreza e ao desamparo da população foram concebidos como não pertencentes aos assuntos do Estado, a resolução de tais problemas foi entregue a homens e mulheres bons, constituiram-se as bases para o desenvolvimento de práticas caritativas pela sociedade, orientadas pelo ideário de caridade Cristã de amor ao próximo. As mulheres aparecem nesse cenário como suas principais praticantes. Esse modelo filantrópico se apresenta na prática de Darcy mesmo anteriormente a criação da LBA, a exemplo da Legião da Caridade, da Fundação Darcy Vargas, da Casa do Pequeno Jornaleiro. "Com a criação da Fundação Darcy Vargas, em 1938, a primeira-dama estabelece, no cenário assistencial do Rio de Janeiro, uma obra destinada à 'infância desvalida'” (SIMILI, 2008, p. 82).

AAssistência praticada por meio dessa filantropia evidencia seu modo de ser, ou seja, é convertida em atendimento de emergência, não se caracterizando em um direito, mas apresentada enquanto uma saída pensada a curto prazo. De acordo com Aldaiza Sposati (1989), a assistência na trajetória das políticas sociais brasileiras é uma forma discriminada e parcial de atender alguns segmentos populacionais excluídos historicamente que, de forma objetiva, não existem para o capital - empregados, indigentes, deserdados, órfãos, etc. Dessa forma, assistência não ecoaria como direito do cidadão, mas como "mérito do necessitado". Como direito, mas sim como um favor emergencial. Esse conjunto de práticas assistencialistas empreendidas pela primeiradama Darcy Vargas, que no decorrer do século XX se constituiu enquanto modelo de atuação das primeiras-damas da nação, pode ser apreendida enquanto uma inversão da cidadania ou a transformação de uma cidadania subalterna (TORRES, 2002, p. 22).

O exercício da benemerência não é instrumento de justiça social. Ele inclui excluindo da cidadania. Práticas pessoais de ajuda estão no âmbito de comportamentos e atitudes pessoais às quais não se interpõe julgamentos de transgressão à lei pelo uso dos recursos privados e próprios. Já a benemerência com dinheiro público se inscreve em outra situação, pois se trata do uso por um dirigente ou seu preposto, do recurso de organização pública. Nesse caso, ingressamos no campo do uso irregular do que é público distribuído em caráter pessoal através de favores dos quais advém benefícios pessoais pecuniários ou políticos. Aqui ocorre a infringência da lei e possível crime de peculato. (SPOSATI, 2002, p. 11)

Cabe aqui uma compreensão sobre esse antagonismo entre assistência e assistencialismo. De acordo com Torres (2002, p. 175), o assistencialismo "trata-se de uma estratégia política que exclui o ser social do processo de participação política no seio da sociedade, promovendo uma cultura do silêncio e um comportamento de passividade a ordem". Entendida como um dos elementos fundamentais do populismo, tal prática permite que o poder utilize-o enquanto estratégia política dentro de suas 
estruturas institucionais, forjando assim, a legitimação junto às classes menos favorecidas da sociedade. Já a assistência social, corroborando com Bobbio (1992, p. 72) "assume o caráter de política pública, como direitos dos cidadãos e que requer uma intervenção ativa do Estado, produzindo aquela organização dos serviços públicos de onde nasceu até mesmo uma nova forma de Estado, o estado social".

Ponto importante a ser destacado é o processo de profissionalização do Serviço Social do Brasil. Caridade, atributos religiosos e presença feminina, foram pontos centrais nesse processo. No Brasil, o Serviço Social nasce atrelado à necessidade da Igreja Católica em se fazer presente na sociedade que passou por um processo de laicização. Para não perder seu posto junto aos mais variados setores sociais, a igreja estende sua ação, se fazendo presente por meio de muitas instituições de cunho social, como as citadas acima. A esse respeito é importante destacar que nos anos 1930 o serviço social começou a ser aceito como profissão feminina, incentivada e ressaudada por diversos intelectuais que a consideravam uma opção profissional a mais para as mulheres, além do magistério, principal atividade profissional atribuída às mulheres na época. Em São Paulo, um relevante marco foi o primeiro Curso de Formação Social realizado em 1932, promovido pelas freiras do colégio Des Oiseaux, que trouxeram da Bélgica mademoiselle Adele de Leneux para ministrá-lo. Ao final do curso foram criados o Centro de Estudos de Assistência Social (CEAS) e a Escola de Serviço Social de São Paulo, criado em 1936. O curso iniciou a sua primeira turma com 14 moças católicas, as quais se tornaram as primeiras assistentes sociais brasileiras (IAMAMOTO, 1992).

Inicialmente atrelado à práticas filantrópicas e assistenciais, a partir dos anos 1960 o curso de Serviço Social e sua prática profissional começam a ser repensados. Adotando uma metodologia crítico-política, o Serviço Social, a partir de então, iniciara um caminho de ação junto ao social, que se institucionalizaria enquanto política por meio da Constituição de 1988. "A assistência social só adquiriu status de política pública a partir de 1988. E somente em 1993 é decretada e sancionada a Lei $n^{\circ}$ 8.742/93, denominada de LOAS - Lei Orgânica da Assistência Social" (TORRES, 2002, p. 23).

No decorrer do século XX, seguindo o modelo instituído por Darcy Vargas, diversas primeiras-damas pontuaram suas ações nos setores da assistência social. Versando entre práticas assistencialistas e políticas públicas de fato, no espaço se tornou constante a presença de esposas de governantes em nosso país. Nos três âmbitos governo-administrativos, municipal, estadual e federal, diversas primeirasdamas aturam nas Secretarias de Serviço Social, ou em outros órgãos destinados ao social.

Longe de almejar generalizações, pode-se pontuar que no Brasil, desde a década de 1940, as atividades exercidas pelas primeiras-damas, iniciadas em caráter de ordem filantrópico-benemerente no âmbito da atenção à pobreza, se estenderam ao campo político. Diversas primeiras-damas passaram a atuar junto a esfera social em órgãos públicos, ligados diretamente à governabilidade dos seus esposos. Ser primeiradama deixou de ser uma posição meramente ilustrativa, passando esta figura social a atuar na esfera pública enquanto representante do Estado.

Esse caminhar, essas estratégias e táticas demonstram a linha tênue que separam atuações protagonistas e coadjuvantes no campo político. É interessante destacar que ser coadjuvante não carrega prerrogativas apenas negativas. Aos olhos dos estudos de gênero precisamos descontruir essas dicotomias criadas em torno do impedimento de atuação criados no que tange a atuação das primeiras-damas. Em diálogo com Bourdieu (2007) e Chartier (2008), essa interdição que marcaria o espaço 
de atuação da figura da primeira-dama se encaixaria no conceito de dominação masculina, caracterizada pela presença da violência simbólica. Os autores ainda ressaltam que para que essa dominação se efetive de fato, ocorre um processo de incorporação por parte dos agentes dominados. No entanto, essa incorporação, salienta Chartier, não exclui a possibilidade de afastamentos e manipulações das experiências.

Dessa forma, em se tratando dos espaços de atuação das primeiras-damas, a conformação dessas mulheres em atuarem nestes, não implica necessariamente uma conformidade esvaziada, mas também pode indicar a possibilidade de construir recursos permitindo o deslocar ou o subverter a relação de dominação. Nessa direção, o permanecer nesses espaços também pode ser visto enquanto uma tática das mulheres que ali estiveram em atuação, e não somente enquanto uma estratégia de perpetuação do poderio masculino, pois, como veremos no decorrer do estudo, diversas primeiras-damas extrapolaram os limites que lhes foram impostos. As relações de gênero se constituem em meio as relações de poder que permeiam o interior das experiências individuais e coletivas, se fazendo e refazendo buscando atender os interesses em voga.

\section{As marcas das desigualdades de gênero nesse papel social}

Recentemente, no dia dezoito de abril de 2016, a Revista Veja divulgou uma nota com o seguinte título, "Marcela Temer: bela, recatada e do lar"7. No dia subsequente, as redes sociais foram tomadas por uma onda de protesto em repúdio a mesma. A nota fazia menção a esposa do vice-presidente do Brasil, Michel Temer, que assumiu a presidência da república pós a saída de Dilma Rousseff. Apontada com mulher "modelo", exemplo e ideário a ser seguido, suas roupas e modos são valorizados, sua postura sempre atuando num segundo plano, atrás de seu marido, e sua dedicação ao lar e ao filho são registrados como padrão de mulher e, mais especificamente, de primeira-dama.

A nota foi uma crítica explícita a ex-presidenta do Brasil, Dilma Rousseff, que, diga-se de passagem, não é portadora de tais atributos. Uma senhora de idade, solteira, de cabelo curto e gorda, características que, aos olhos da Revista Veja, parecem se sobrepor a sua qualificação profissional, seus feitos na política, sua popularidade junto a população e sua legítima vitória nas urnas no pleito de 2014. Para além e aquém da referida crítica a presidenta da república, o noticiário evidencia a supervalorização da feminização da mulher, colocando todas aquelas que não se encaixam nela, a margem de uma aceitação social. A Revista resgata uma série de preceitos e qualidades atreladas historicamente a condição de primeira-dama.

Desde sua gênese, foi atribuída à figura de primeira-dama uma série de estereótipos estigmatizantes. "A imagem social que se constrói em torno delas é de mulheres abnegadas, vocacionadas e sensíveis às causas sociais" (TORRES, 2002, p. 25). Somando a isto, valoriza-se sua atuação na esfera privada, sua dedicação aos afazeres do lar, ao cuidado dos filhos, a sua posição secundária em relação a seu esposo.

As primeiras-damas fazem uso de uma mística feminina para legitimar enquanto acompanhantes de seus esposos. Como afirma Ivanildes Torres, "a representação de papeis sociais de primeira-dama envolve uma dimensão simbólica que evoca valores

\footnotetext{
7 Ver nota na íntegra em: http://veja.abril.com.br/noticia/brasil/bela-recatada-e-do-lar. Acesso em 25 de abr.
} 2016. 
cristãos, a figura do líder carismático e concepção de gênero fundadas na cultura do patriarcado" (TORRES, 2002, p. 192-193). Esse patriarcado, ainda vivenciado nos dias de hoje, mesmo que em moldes diferenciados, atribui às mulheres primeiras-damas uma condição subjugada a um segundo plano. Essa é a posição ocupada por muitas esposas de governantes, é a posição apontada como ideal de se portar. No entanto, devemos destacar que nem todas aquelas mulheres que assumiram a posição de primeira-dama se encaixaram nessa mística. Algumas delas, vale mencionar, ultrapassaram as barreiras da atuação privada e coadjuvante na cena política, se inserindo de fato no jogo de poderes do mundo político.

A constituição do espaço público enquanto masculino, em detrimento do privado enquanto feminino esteve inserido no modelo de sociedade moderna ocidental. Nessa conjuntura os papéis de gênero são socialmente constituídos. "Dentro dessa convivência social, são construídos os papeis sociais, os clichês, as estereotipias, os comportamentos, os modos de vestir, enfim, são efetivados todos os tipos de condicionamentos cristalizados o desempenho de papeis" (TORRES, 2002, p. 45). Nesse processo de construção estão envolvidos padrões de conduta e de comportamentos que são afirmados e reforçados nos discursos normativos, nas orientações de cunho religioso, jurídico e moral, a exemplo do discurso da Igreja Católica, que constituiu uma rede de tabus reforçando a visão da mulher enquanto frágil, dependente e submissa; o discurso da medicina, ao pontuar por séculos a importância da mulher para procriação, a maternidade; a rede educacional, que diariamente reafirma as desigualdades de gênero na sala de aula. Essa constituição de esferas separadas faz parte do que Carole Paterman denominou de contrato original, mas este não omitindo sua parte invisibilizada até então pelos críticos dos teóricos do contrato. A parte silenciada seria o contrato sexual, que em conjunto com o contrato social teriam dado origem ao contrato original. Este contrato seria baseado no pressuposto de igualdade e de sujeição, sendo este às mulheres e aquele aos homens. Esta seria toda a base de constituição do patriarcado moderno.

De acordo com Foucault todos esses elementos fazem parte de um conjunto de dispositivos normativos presentes na sociedade moderna. Tais dispositivos enquadram os "iguais e normais", excluindo todos aqueles indivíduos que não se encaixam nos padrões pré-estabelecidos. Nesse sentido, Simili (2008, p. 32-33) destaca que:

particularmente no final do século XIX e início do século XX, nos saberes
hegemônicos - médico, político, jurídico, literário e pela imprensa -, os conceitos de
público e de privado serviram para criar representações acerca dos espaços de
atuação para homens e mulheres, com base em pressupostos sexistas. Nessas
Representações, o poder e a política aparecem como atividades masculinas, pela
capacidade e pelas habilidades "naturais" do homem para a racionalidade, para o
controle das emoções e para a tomada de decisões, entre outras características e
competências. E a vida privada como espaço feminino, pelas qualidades e
propensões também "naturais" das mulheres para casa, a família e a maternidade.

Pioneira, enquanto primeira-dama, no trabalho junto à assistência, Darcy Assume a presidência da LBA, com intuito de complementar as ações políticas de seu esposo, sem jamais buscar disputar espaço e poder com Getúlio. A estruturação do papel de primeira-dama pode ser pensando enquanto perpetuação de uma das dicotomias que estão na base da desigualdade de gênero. O homem, Presidente da República, ao lado da razão, a mulher, primeira-dama da Nação, ao lado dos sentimentos, responsável pelo cuidado. Vale lembrar que no decorrer da década de 
1930 a questão social ainda era bastante banalizada, sendo, desta forma, "repassada" a algumas mulheres o encargo de suas responsabilidades, tendo em vista que o Estado não tinha objetivos claros de intervenção.

Darcy Vargas se apresenta como uma mulher pública que trouxe suas habilidades e qualidades privadas para o público. A esse respeito ressalta Torres (2002, p. 58):

Os papéis de primeira-dama assentam-se nesses valores ditos femininos, em que sentimentos de bondade e de solidariedade acabam sobrepondo os níveis de racionalidade das atividades assistenciais desenvolvidas por essas mulheres. $\mathrm{Na}$ verdade, há uma apropriação por parte do poder local dos valores atribuídos às mulheres para firmar uma base de legitimação à ordem estabelecida. Todavia, elas não têm consciência dessa apropriação e dominação masculina frente aos valores e as pessoas, o que denota uma certa naturalização dos papeis sociais.

Lembrando que a prática da caridade não é algo novo na sociedade brasileira, e que a presença das mulheres nelas é algo constante, deve-se abrir um parêntese e destacar que em se tratando do trabalho caritativo e benevolente das primeiras-damas há um componente político bem definido. Seria a apropriação do poder estatal dessas práticas das mulheres para se legitimar no poder. As ações das primeiras-damas são efetivadas buscado apresentar uma imagem do estado enquanto benfeitor, aparecendo como benevolente e preocupado com as causas sociais. "Assim, as primeiras-damas, com as suas atividades assistencialistas e benevolentes, acabam dando sustentação política ao poder local, materializada na legitimação popular ao governo por elas conquistada com seu trabalho, encarado pelos setores subalternos como ações humanitárias realizadas pelos próprios governantes" (TORRES, 2002, p. 58-59).

A primeira-dama se tornou a figura feminina historicamente marcante com relação à assistência, em diversas épocas. A representação e a reprodução da imagem que a primeira-dama transmite para a população favorecem a sua legitimação enquanto figura pública, e são mantidas por serem necessárias aos interesses daqueles que estão no poder. Ela é projetada para reforçar a ideia que congrega a mulher/benfeitora e sensível às práticas de atendimento aos mais pobres e necessitados, enraizada na sociedade brasileira. (SILVA, 2009, p. 16)

A figura da primeira-dama estaria diretamente relacionada a uma certa identidade de gênero, na qual à mulher caberia as atividades do cuidado. Projetada para ser executada pela esposa do governante, assumiu a frente das demandas sociais da nação, principalmente aquelas que estivessem à margem do modelo de cidadania idealizado pelo Estado Novo8. Tais fatores evidenciam como as relações de gênero estão permeadas por relações de poder em vários sentidos, quer pelo fato de algumas mulheres que contribuíram para o prestígio e poder político dos homens, quer pela conquista de poderes próprios, como, por exemplo, aqueles que se conquistaram no interregno de sua prática social. "Nesse sentido, o poder político com o qual as primeiras-damas mantém relações também passa a ser visto sob aspecto da Bondade. Assim, a imagem que se produz da primeira-dama no Imaginário coletivo pode vir a ser instrumento de Constituição de poderes próprios e de legitimidade do Poder constituído" (TORRES, 2002, p. 193).

\footnotetext{
${ }^{8}$ Como salienta Capelato (2013), durante o Estado Novo a noção de cidadania estava ligada ao trabalho, ou seja, cidadão era o trabalhador. Este, por sua vez, carregada consigo prerrogativas de deveres e direitos junto ao Estado.
} 
Nos referimos a poder corroborando com o pensamento de Foucault, que o compreende nos meandros da sociedade, sobretudo em suas múltiplas formas espalhadas por diferentes práticas sociais. É assim que o filósofo faz uma ruptura com a visão tradicional que entendia o poder presente única e exclusivamente no âmbito do Estado e das instituições, como se somente essas instâncias fossem um lócus indubitável da prática do poder. Assim, Foucault demonstra que existem poderes fora do aparato institucional e destaca que eles se estabelecem no tecido social e proliferam criando relações pessoais, interpessoais, coletivas hierárquicas. As ações das primeiras-damas são entendidas como formas de poder, ou de micropoderes, mesmo estando atrelada aos fazeres do Estado.

\section{Ser coadjuvante ou protagonista: eis um paradoxo}

Diante desse contexto de constituição do papel social da primeira-dama e sua perpetuação no decorrer dos séculos XX e XXI, questionamos então o protagonismo ou a ausência deste na atuação dessas mulheres. A participação de Darcy Vargas na criação da Legião Brasileira de Assistência, bem como no desenvolvimento de práticas políticas assistenciais e benevolentes podem ser entendidas como marco significativo na história das mulheres e na história da política assistencial, visto que se trata do primeiro momento em que uma mulher passou a ocupar um cargo de direção na política social. Ao criar a LBA a primeira-dama da nação assume sua presidência, incumbindo as demais primeiras-damas deste papel.

Na primeira metade do século $X X$ algumas mulheres participaram ativamente das lutas em prol do sufragismo. Não foi o caso de Darcy Vargas, que por meio de sua prática "desenhou" um modelo de atuação para as esposas de governantes. Pode-se destacar, então, que foram tipos de protagonismos diferentes, se levarmos em conta que nos dois eixos de atuação as mulheres ultrapassam os limites do espaço privado.

Diante desse contexto a política partidária se apresenta enquanto parte da atuação na vida pública, cabendo aos homens sua participação nele. Nesse ínterim, corroborando com Bourdieu (2011), apontamos a política partidária enquanto parte do campo político. O sociólogo aponta que tudo aquilo que é passível de ser pensado e falado politicamente é limitado pelas leis que regulam o campo da política. Nesse sentindo, o autor entende por noção de "campo", a conjuntura de relações entre as posições desempenhadas pelos agentes, de acordo com suas colocações nas distribuições e lutas de poder, sendo a existência dessas relações independente da consciência e intenção individual. Na mesma direção Rabay e Carvalho (2010) inspiradas em Bourdieu salientam que "a política é uma instituição corporativa de representação de interesses, com normas próprias de recrutamento e de treinamento político" (RABAY; CARVALHO, 2010, p. 33).

No interior desse campo os agentes políticos produzem e seguem as regras e normas construídas, atuando mediante seu reconhecimento junto àqueles que os elegeram, ou Ihes depositaram confiança para representá-los. Dessa forma, o campo político pode ser apontado tanto como campo de forças, quanto como campo de lutas, não estando este alheio à conjuntura à sua volta, muito pelo contrário, dialogando e respondendo o tempo inteiro a fatores externos. (RODRIGUES, 2017, p. 21)

A reflexão nos escritos de Bourdieu (2011, p. 97) evidencia certa exclusão das mulheres do campo político ou do jogo do poder. Seu confinamento no universo 
doméstico faz com que elas sejam preparadas para participar do campo político "por procuração", ou seja, por intermédio dos homens que nem eles estão envolvidos, maridos ou filhos. Dessa forma, "pelos homens, as mulheres participam dos jogos dos quais estão excluídas" (SIMILI, 2008, p. 36).

O papel de primeira-dama, enquanto colaboradora das ações governamentais, tanto pode ser entendido enquanto forma de protagonismo, tanto quanto de coadjuvante. No entanto, sua participação no jogo político é incontestável. Segundo Norberto Bobbio (1992) a expressão "participação política" é polissêmica, podendo ser utilizada de diferentes formas. Por participação, pode-se conceber participar ou tomar parte de algum acontecimento político de modo diferenciado, desde a condição de simples espectador mais ou menos secundário até a de protagonista de destaque. Assim, por vezes de forma mais atuante, por vezes nem tanto, as primeiras-damas exerceram uma participação na política nacional.

Darcy Vargas inicia sua participação junto à Getúlio antes mesmo de se tornar primeira-dama do país. Em andamento os preparativos para o movimento de 1930, Darcy tem sua participação marcada pela criação da Legião de Caridade, além de se mostrar envolvida com o planejamento do movimento.

Os dias continuavam iguais, mas as noites eram sempre diferentes até o dia 3 de outubro. Às 8 horas da manhã fomos para o colégio e voltamos às 4 horas da tarde, como habitualmente. Mamãe não esperava à porta. Mandou Manoel Antônio e Getúlio tirarem o uniforme rapidamente e me chamou com o ar preocupada: "a revolução vai arrebentar hoje às 5 h15 e não quero que vocês Durmam aqui. Irão para casa de uns amigos nossos". Quis reagir, mas preferia ficar. "Você tem que ir para tomar conta de seus irmãos", disse com sua irretorquível voz de comando. (PEIXOTO, 1960, p. 37)

Darcy sabia de todo o plano referente a revolução que iria explodir, como salienta Simili (2008, p. 38).

\begin{abstract}
Esse trecho sugere que a participação de Darcy na trama da revolução foi muito além de "abrir a porta" para os revolucionários. Ela havia acompanhado o desenrolar das articulações políticas e, passando a frase em que o segredo era a peça chave para o sucesso do empreendimento político, enquanto o Getúlio atende os "conspiradores", Darcy se arranja e se entende com as "mulheres dos conspiradores".
\end{abstract}

A articulação de Darcy com essas mulheres foi parte do instrumento político importante na Revolução de 1930. Segundo Alzira Vargas, a fórmula encontrada pela mãe para auxiliar na causa revolucionária foi a legião de caridade. "Foi para ajudar o marido e sua luta que ela organizou a legião. Ao dizer que a mãe fundara uma associação filantrópica para ajudar as famílias dos revolucionários, a filha Alzira procura atribuir um papel de colaboradora do pai, de apoio à sua causa" (SIMILI, 2008, p. 39).

Iniciada sua atuação enquanto primeira-dama, Dacy Vargas dá continuidade a sua participação junto a seu esposo. Agora ela assume a presidência da Legião Brasileira de Assistência, tomando a frente dos problemas sociais do país. Nos anos 1930 e 1940, participaram do processo de construção da personagem Darcy Vargas a continuidade de uma posição na família de mãe e esposa, e a criação de um percurso marcado pelo envolvimento com as políticas públicas para a infância e para o social. Constrói-se a identidade de uma mulher múltipla e fracionada, uma mulher que vai ao público sem sair do privado. 
Como destaca Sposati, "atenção, não era um movimento feminino ou feminista mas 'a arte política' da esposa do político mostrando o caráter humanitário do governo, agindo como apêndice do governante para área de ação social sob ótica totalmente assistencialista" (Sposati, 2002, p. 09). Eram mulheres agindo, com maior ou menor autonomia, face ao líder que ocupava o governo.

Na construção dessa mulher pública, é possível identificar aquilo que Darcy Vargas emprestou e deixou à disposição do Poder no Exercício do presidente: suas habilidades pessoais, sua simpatia, sua maneira de ser, enfim, "seu gesto, posturas, olhares e comportamentos da mulher que ela era". Desses e com esses materiais, foram elaborados seus poderes sociais, políticos e simbólicos", que ela utilizou no exercício de seu poder. (SIMILI, 2008, p. 161)

Figura feminina, que valoriza os atributos ditos "femininos", que superestima a presença da mulher no espaço público sem abrir mão do privado, aquela que auxilia e legitima as ações dos governos administrados por seus esposos, esta é a imagem social construída em torno do papel da primeira-dama. Na artigo intitulado Oportunidades e obstáculos familiares para o acesso das mulheres à política, Rabay; Rodrigues; Silva $(2017)^{9}$ destacam as dificuldades das primeiras-damas para adentrar a política partidária, tendo em vista que muitas delas só conseguem tal acesso devido a algum impedimento de seu cônjuge. Se levarmos em conta os apontamentos de Bourdieu (2011), de que aqueles/las que não possuem um conhecimento peculiar, que se configura enquanto capital cultural, constituindo-se em capital político, terão que delegar representantes aparentemente aptos, ou profissionalizados, à realização da chefia política. Ou seja, ou se tem o conhecimento necessário e pertinente ao campo político para poder nele adentrar e permanecer, ou lhe caberá o exercício de escolher seus representantes que, por ventura, devam ter determinados conhecimentos. A política é apontada dessa forma como um campo monopolizado por profissionais a ele adaptados. Dessa forma, os que almejam adentrar o referido espaço devem se adequar às regras do campo político, para assim adentrar e nele permanecer.

Ao observar a trajetória das prefeitas eleitas no estado da Paraíba para a legislatura de 2013 a 2016, (o trabalho se pautou na análise de 23 das 49 eleitas na ocasião), as autoras observaram que dentre as entrevistadas quinze eram ou já haviam sido casadas com políticos, tendo exercido o papel de primeira-dama antes de adentrarem a política partidária enquanto candidatas. Ao analisar as falas dessas prefeitas as autoras destacam os empecilhos encontrados por serem esposas de homens políticos. Todas elas afirmaram haver participado anteriormente dos governos de seus cônjuges, seja no processo de campanha eleitoral, seja atuando em alguma secretaria das respectivas prefeituras. Com isso, pode-se concluir que elas seriam portadoras de certo capital político próprio, ou, nas palavras de Bourdieu, possuíam certo treinamento necessário para a atuação na política partidária. No entanto, a entrada delas enquanto candidatas só ocorre devido a algum impedimento da candidatura de seus esposos. Nessa conjuntura, o capital político familiar adquirido de seu esposo colabora para que esta mulher seja eleita para algum cargo político, porém, enquanto estes homens podem atuar no campo político, reservam as suas esposas apenas um

9 RABAY, Gloria de Lourdes Freire; RODRIGUES, Dayanny Deyse Leite; SILVA, Lucimeiry Batista da. Oportunidades e obstáculos familiares para o acesso das mulheres à política. 13 Women's Worlds Congress \& Seminário Internacional Fazendo Gênero - Transformações, Conexões, Deslocamentos. FlorianópolisSC. 30 de julho a 04 de agosto de 2017.; 
papel por trás das cortinas do palco principal da política.

O papel de primeira-dama figura-se entre o protagonismo e o coadjuvantismo. Vale destacar que embora esse papel social tenha sido pensado e elaborado como meio de suporte às práticas dos esposos governantes, muitas primeiras-damas exerceram papel de destaque, construindo trajetórias de atuações próprias. A esse respeito Torres destaca que "é importante atentar para o fato de que nem sempre o poder local determina as 'regras do jogo' às primeiras-damas. Há casos em que ocorre o contrário: é a primeira-dama quem dá o norte ao governo no âmbito da promoção social. [...] Portanto, não há um único padrão de comportamento para as primeiras-damas" (TORRES, 2002, p. 50).

Nessa perspectiva de atuações próprias, Torres destaca que "Os dados revelam que em alguns casos as mulheres primeiras-damas possuem mais popularidade do que o marido governante" (TORRES, 2002, p. 12). Evidenciar tal ponto nos leva a observar as primeiras-damas de forma menos instrumentalizada, não as enxergando enquanto objetos dos poderes do Estado. "As mulheres estão construindo o seu próprio espaço, portanto não nos parece convincente atribuir absoluta subalternidade às primeirasdamas" (TORRES, 2002, p. 21-22).

O centro dessa discussão consiste no reconhecimento de que há um campo de relações de poder envolvendo mulheres na esfera do que Foucault (1993: XII) denomina de micropoder 'que se situa ao nível do próprio corpo social, e não acima dele, penetrando na vida cotidiana e, por isso podendo ser caracterizado como micropoder ou subpoder'. (TORRES, 2002, p. 22)

Aos poucos, muitas mulheres primeiras-damas foram se colocando na esfera pública como sujeitos políticos de decisão e de gestão, revelando grande potencial de liderança e poder de persuasão junto aos sujeitos sociais com quem travam relações. Dessa forma, destacamos que a participação política das primeiras-damas no decorrer dos séculos $X X$ e XXI ocorreu de forma transitorial entre estar num segundo plano, agindo enquanto legitimadoras dos anseios governamentais, e fazer uso de suas experiências para a constituição de capitais políticos próprios e assumir papeis protagonistas no campo político, a exemplo de Sara Kubitschek e Maria Thereza Goulart. Sara criou e presidiu um grupo denominado Pioneiras Sociais, agindo em paralelo aos trabalhos desenvolvidos pela LBA. O grupo se destacou principalmente na assistência à saúde. Maria Thereza atuou junto a Legião Brasileira de Assistência.

\section{Referências}

AMARAL, Isabel. Primeira-dama, o que é? Madrid, 28 de Fevereiro de 2007 (Palestra proferida por Isabel Amaral, na EIP - Escuela Internacional de Protocolo - em Madrid, Espanha, no dia 28 de Fevereiro de 2008). Disponível em: http://br.monografias.com/trabalhos913/primeira-dama/primeira dama2.shtml. Acesso em 15 de setembro de 2017.

BOBBIO, Norberto. Dicionário de Política. 4 ed. Brasília: Editora da UnB, 1992. v.2.

BOURDIEU, Pierre. O Poder Simbólico. Tradução Fernando Tomaz (português de Portugal) - 15. ed. - Rio de Janeiro: Bertrand Brasil, 2011.

CALLADO, Ana Arruda. Darcy, a outra face de Vargas. Rio de Janeiro: Betel, 2011.

CHARTIER, Roger. (2008). Diferenças entre os sexos e dominação simbólica (nota 
crítica). Cadernos Pagu, (4), 37-47. Disponível em: https://periodicos.sbu.unicamp.br/ojs/index.php/cadpagu/article/view/1761. Acesso em 30 de out. 2019.

CAPELATO, Maria Helena. O Estado Novo: o que trouxe de novo? In: FERREIRA, Jorge; DELGADO, Lucília de Almeida Neves (Orgs). O Brasil Republicano. O tempo do nacionalismo-estatísmo - do início da década de 1930 ao apogeu do Estado Novo. Livro 2. Rio de Janeiro: Civilização Brasileira, 2003. p. 107-114.

FALCÃO, Maria do Carmo B. C. As primeiras-damas ressurgem na era Collor. In: Serviço Social \& Sociedade. Ano XI, N 33. São Paulo: Editora Cortez, 1990.

FOUCAULT, M. História da Sexualidade I: a vontade de saher. Trad. M.T. C. Albuquerque e J. A G. Albuquerque. Rio de Janeiro: Graal, 1977.

FOUCAULT, M. Microfísica do Poder. Organização e introdução de Roberto Machado. 3.ed. Rio de Janeiro: Graal, 1982.

IMAMOTO, M. V. Renovação e conservadorismo no Serviço Social. Ensaios Críticos. 15 ed. São Paulo: Cortez, 1992.

IAMAMOTO, Marilda Villela. Relações Sociais e Serviço Social no Brasill. 9. ed. - São Paulo: Cortez, 2009.

MARCÍLIO, Maria Luiza. História Social da criança abandonada. São Paulo: Hucitec, 1998.

PATEMAN, Carole. O Contrato Sexual. Tradução de Marta Avancini. Rio de Janeiro: Paz e Terra, 1993.

Pinottti M. et Al. O Serviço Social no Brasil. Rio de Janeiro: Legião Brasileira de Assistência, 1958.

RABAY, Gloria; CARVALHO, Maria Eulina Pessoa de. Mulher e Política na Paraíba. Histórias de vida e luta. João Pessoa: Assembleia Legislativa da Paraíba: Editora da UFPB, 2010.

RABAY, Gloria de Lourdes Freire; RODRIGUES, Dayanny Deyse Leite; SILVA, Lucimeiry Batista da. Oportunidades e obstáculos familiares para o acesso das mulheres à política. 13 Women's Worlds Congress \& Seminário Internacional Fazendo Gênero Transformações, Conexões, Deslocamentos. Florianópolis-SC. 30 de julho a 04 de agosto de 2017.

Regimento Interno da Casa do Pequeno Jornaleiro disponível em: http://www.fgv.br/cpdoc/acervo/arquivo-pessoal/AVAP/textual/documentos-sobre-afundacao-darcy-vargas-e-a-casa-do-pequeno-jornaleiro-como-pedidos-votos-depesames-congratulacoes-cartas-de-apresentacao-agrade. Acesso em 12 de fevereiro de 2018.

RODRIGUES, Dayanny Deyse Leite. Mulheres e política no estado da Paraíba: a atuação de Lúcia Braga em meio às práticas políticas locais. Dissertação (Mestrado em História). Centro de Ciências e Letras, Universidade Federal da Paraíba. João Pessoa, p. 211. 2017.

RODRIGUES, Dayanny Deyse Leite. RABAY, Glória. USOS E ABUSOS DO TERMO "PRIMEIRA-DAMA": uma discussão de gênero. VI Seminário Nacional Gênero e 
Práticas Culturais: interfaces com as relações étnico-raciais. João Pessoa - PB. 22 a 24 de novembro de 2017. Anais Eletrônicos do VI Seminário Nacional Gênero e Práticas Culturais: interfaces com as relações étnico-raciais - 22 a 24 de novembro de 2017. Organizadores: Maria Lúcia da Silva Nunes/ Charliton José dos Santos Machado/Shirley Targino Silva (Orgs.). Fortaleza: EdUECE, 2018. ISSN: 2447-5416. Disponível em: . https://visngpc.com/anais/.

SANTOS, Wanderley Guilherme dos. Cidadania e Justiça. A política social na ordem brasileira. 3 ed. Rio de Janeiro: Campus, 1994.

SILVA, Lianzi dos Santos. Mulheres em cena: as novas roupagens do primeiro damismo na assistência social/Lianzi dos Santos Silva; orientadora: Ana Maria Quiroga. - 2009. Dissertação (Mestrado em Serviço Social) Pontifícia Universidade Católica do Rio de Janeiro, Rio de Janeiro, 2009.

SIMILI, Ivana Guilherme. Mulher e Política: A Trajetória da Primeira- Dama Darcy Vargas (1930-1945). São Paulo: Editora UNESP. 2008.

SPOSATI, Adaílza. Prefácio. In: TORRES, Iraildes Caldas. As primeiras-damas e a assistência social: relações de gênero e poder. São Paulo: Cortez, 2002.

SPOSATI, Adaílza; FALCÃO, Maria do Carmo. LBA, identidade e afetividade das ações. São Paulo: Educ, 1989.

TORRES, Iraildes Caldas. As primeiras-damas e a assistência social: relações de gênero e poder. São Paulo: Cortez, 2002.

VARGAS, Alzira. Getúlio Vargas, meu pai. Rio de Janeiro: Editora Globo, 1960.

VARGAS, Getúlio. Diário. São Paulo: Fundação Getúlio Vargas, 1995. V.1.

\section{Notas de autoria}

Dayanny Deyse Leite Rodrigues é graduada e mestre em História pela Universidade Federal da Paraíba. Especialista em História do Brasil e da Paraíba. Especialista em Gênero e Diversidade na Escola. Doutoranda em História pelo Programa de Pósgraduação em História da Universidade Federal de Goiás. Bolsista Capes. Email: dayannydeyse@hotmail.com.

Como citar esse artigo de acordo com as normas da revista

RODRIGUES, Dayanny Deyse Leite. Ser coadjuvante ou protagonista no cenário político: o impasse das primeiras-damas. Sæculum - Revista de História, v. 24, $n^{\circ} 41$, p. 176-195, 2019.

\section{Contribuição de autoria}

Não se aplica.

Consentimento de uso de imagem

Não se aplica.

Aprovação de comitê de ética em pesquisa

Não se aplica.

\section{Licença de uso}


Este artigo está licenciado sob a Licença Creative Commons CC-BY. Com essa licença você pode compartilhar, adaptar, criar para qualquer fim, desde que atribua a autoria da obra.

\section{Histórico}

Recebido em 25/07/2019.

Aprovado em 10/10/2019. 